\title{
Gelatin films with very high surface hardness
}

\author{
Elena Vassileva*, Francisco J.Baltá Calleja, \\ M.Esperanza Cagiao, Stoyko Fakirov* \\ Instituto de Estructura de la Materia, CSIC \\ Serrano 119, 28006 Madrid, Spain
}

Keywords: microhardness, gelatin films, crosslinking.

Paper submitted to: Macromolecular Rapid Communications.

November, 1997

\footnotetext{
"Permanent address: Laboratory on Structure and Properties of Polymers, Sofia University, 1126 Sofia, Bulgaria.
} 


\section{Gelatin films with a very high surface hardness.}

Elena Vassileva, Francisco J.Baltá Calleja, M. Esperanza Cagiao, Stoyko Fakirov.

\section{Summary}

Gelatin cast film from water solution and annealed for 5 hours at $90^{\circ} \mathrm{C}$, followed by drying in vacuum for another 5 hours at $80^{\circ} \mathrm{C}$ was tested with respect to its microhardness (H) at elevated temperatures in the $100-250^{\circ} \mathrm{C}$ range. Hardness measurements were performed repeatedly on the same sample, each cycle starting at $90^{\circ} \mathrm{C}$ and finishing at a given temperature between the glass transition temperature $\mathrm{T}_{\mathrm{g}}=217^{\circ} \mathrm{C}$ and the melting temperature $\mathrm{T}_{\mathrm{m}}=235^{\circ} \mathrm{C}$. A strong $\mathrm{H}$ increase with temperature rise is observed, i.e. from $330 \mathrm{MPa}$ up to $449 \mathrm{MPa}$ in the first cycle. In addition, $\mathrm{H}$ values reached in each cycle are higher than those obtained in the previous ones. The extremely high $\mathrm{H}$ values exhibited for thermally treated gelatin surpass the hardness of all the commercial synthetic polymers and soft metals known. These values are explained in terms of the densification effects arising from crosslinking as a result of additional intra- and intermolecular condensation between side-chain free carboxylic, hydroxylic and amino groups within the protein molecules. 


\section{Introduction}

In a recent study ${ }^{1 /}$ on the melting behaviour of gelatin film, it was found that this rather common biopolymer is characterized by very high surface microhardness $(\mathrm{H})$. It turned out that in this respect it surpasses all commercial synthetic polymers, characterized by microhardness values typically varying between 100 and $250 \mathrm{MPa}{ }^{2)}$. Room conditioned gelatin, i.e., containing about $15 \mathrm{wt} \%$ water, the latter having strong plasticizing (softening) effect, as concluded from the drop of the glass transition temperature $\mathrm{T}_{\mathrm{g}}$ (from $217^{\circ} \mathrm{C}$ to $\left.60^{\circ} \mathrm{C}\right)^{3)}$, shows a relatively high microhardness value - about $200 \mathrm{MPa}$. As a result of the rise in temperature the microhardness gradually increases, reaching the value of $390 \mathrm{MPa}$ in the range $130-150^{\circ} \mathrm{C}^{1)}$. It is assumed ${ }^{1)}$ that this doubling in the microhardness value is correlated, both, to the crystallization process and to the dry state of the sample - at 130 $150^{\circ} \mathrm{C}$ gelatin is completely dried, as found earlier by differential scanning calorimetry (DSC), and gravimetric measurements ${ }^{4)}$.

This strong temperature influence on microhardness motivated our further interest in the microhardness behaviour of gelatin at higher temperatures, covering the ranges of glass transition and melting of dry gelatin $\left(217^{\circ} \mathrm{C}\right.$ and $235^{\circ} \mathrm{C}$, respectively $\left.{ }^{3)}\right)$.

The microindentation technique has been used for the surface hardness characterization because of its simplicity and high sensitivity. During the last two decades, it was demonstrated that this method provides information about the microstructure of polymers, e.g., relationships between microhardness and crystallinity, crystallite perfection, chain conformation and other structural parameters ${ }^{25,6)}$. 


\section{Experimental part}

Microhardness was measured at elevated temperature using a Leitz tester equipment with a square-based diamond indenter and a hot stage. The microhardness values (in $\mathrm{MPa}$ ) were derived from the residual projected area of indentation according to the expression ${ }^{3)}$ :

$$
\mathrm{H}=\mathrm{k}\left(\mathrm{P} / \mathrm{d}^{2}\right)
$$

where $d$ is the length of the impression diagonal in meters, $P$ the contact load applied in $\mathrm{N}$ and $\mathrm{k}$ is a geometric factor equal to 1.854 . A loading cycle of $0.1 \mathrm{~min}$. and a load of $2 \mathrm{~N}$ were used. Measurements from 10 indentations were averaged for each point. Since the values of $T_{g}$ an $T_{m}$ of dry gelatin obtained by microhardness tests deviated from the reported ones ${ }^{3)}$ as well as from those derived by DSC using the same samples ${ }^{17}$, a calibration of the hot stage temperature was performed using crystals of organic compounds. The test substances were placed on the surface of the gelatin film where microhardness was measured. A good correlation between the temperatures read in the hot stage and the true ones in the range of interest $\left(70-210^{\circ} \mathrm{C}\right)$ was found.

The gelatin films were prepared from food grade powder (Merck), soaked overnight at $5^{\circ} \mathrm{C}$, then dispersed at $50^{\circ} \mathrm{C}$ (water bath) and cast in aluminum dishes. The roomconditioned gelatin film (15-17 wt \% water) was further dried for $5 \mathrm{~h}$ at $140^{\circ} \mathrm{C}$ under vacuum and thereafter moistened up to $11 \mathrm{wt} \%$ water content in order to depress the $\mathrm{T}_{\mathrm{g}}$ by a known amount of water. This sample was subjected to annealing for $5 \mathrm{~h}$ at $90^{\circ} \mathrm{C}$ in a vessel containing water to produce low melting crystallites, followed by drying for $5 \mathrm{~h}$ at $80^{\circ} \mathrm{C}$ under vacuum in the absence of water. The film thus treated was repeatedly tested on the hot stage starting by 
$100^{\circ} \mathrm{C}$. Measurements of $\mathrm{H}$ were performed on the same sample, however reaching different temperatures in the range of $T_{g}$ and $T_{m}$ after cooling down to room temperature for each cycle. The sample was stored in a dessicator at room temperature between the cycles.

\section{Results and discussion}

The temperature dependence of microhardness for the gelatin film treated as described above is shown in Figure 1. For the sake of comparison, the $\mathrm{H}$ value of around 200 $\mathrm{MPa}^{1)}$ of room conditioned gelatin is also given (Figure la, the open circle).

One can see that the first heating from $100^{\circ} \mathrm{C}$ up to $191^{\circ} \mathrm{C}$ (Figure la) results in a microhardness increase from 330 to $450 \mathrm{MPa}$. After cooling down to room temperature and then heating up from 100 to $205^{\circ} \mathrm{C}$ (Figure $1 \mathrm{~b}$ ), a further $23 \%$ increase in microhardness is observed, as compared to the maximum value reached in the foregoing measurement (Figure la).

The third series of measurements after cooling down to room temperature, starts at a microhardness value of about $530 \mathrm{MPa}$ at $100^{\circ} \mathrm{C}$ and reaches the highest value of $654 \mathrm{MPa}$ at $196^{\circ} \mathrm{C}$ after which it drops up to $510 \mathrm{MPa}$ (Figure 1c). This confirms the tendency of microhardness to decrease at temperatures above $200^{\circ} \mathrm{C}$. The observed decrease in the microhardness around $200^{\circ} \mathrm{C}$, i.e., close to $\mathrm{T}_{\mathrm{g}}$ of dry gelatin ${ }^{1,3)}$, is presumably related to the softening of the sample.

The last run for the temperature range of $100-200^{\circ} \mathrm{C}$ (Figure 1d) reveals an almost constant microhardness value (between 630 and $565 \mathrm{MPa}$ ) followed by a strong drop to 390 MPa during the next $50^{\circ} \mathrm{C}\left(200-250^{\circ} \mathrm{C}\right)$. This is most probably due to softening effects of the material above its $T_{g}$.

What could be the reason for the observed extremely high values of microhardness of the gelatin films measured at relatively high temperatures, near $T_{\mathfrak{g}}$ and $T_{m}$ for dry gelatin 
(Figure 1)? Before trying to answer this question, to get a better idea about the relative values of the measured microhardness let us recall the experimental microhardness values for some typical commercial polymers and metals.

Paraffins, polyethylenes (PE) and metals, such as $\mathrm{Pb}$ and $\mathrm{Sn}$, exhibit microhardness values below $100 \mathrm{MPa}$; semicrystalline poly(oxymethylene), poly(ethylene terephthalate), extended-chain PE, poly(ethylene 2,6 naphtalate) and metals, such as $\mathrm{Al}, \mathrm{Au}, \mathrm{Ag}, \mathrm{Cu}$ and $\mathrm{Pt}$, show values between 100 and $300 \mathrm{MPa}$; carbon fiber-reinforced polymer composites present values between 400 and $1000 \mathrm{MPa}{ }^{7}$; common metals, such as $\mathrm{Zn}$ and $\mathrm{Co}, 2000$ and 4000 $\mathrm{MPa}$, respectively; white steel $5000 \mathrm{MPa}{ }^{2)}$. Thermally untreated gelatin with its microhardness of $390 \mathrm{MPa}{ }^{1)}$ really surpasses all commonly used synthetic polymers and soft metals. Thermally treated gelatin with a microhardness value of almost $700 \mathrm{MPa}$ is in the range of the carbon fiber-reinforced composites ${ }^{7}$.

One might assume that these unusually high values of $\mathrm{H}$ for dried and particularly thermally treated films could be originated by the elastic recovery of the sample surface after removing the indenter resulting in smaller indentation sizes, i.e. higher $\mathrm{H}$ values ${ }^{5)}$. In order to check this assumption, additional experiments with different loads were performed. It was found that, for a room conditioned sample exhibiting a hardness value of around $200 \mathrm{MPa}$ (Fig. 1a) there was no elastic recovery at all. On the other hand, for the dried samples measured at $\mathrm{T}=160^{\circ} \mathrm{C}$ the elastic recovery caused an increase of $\mathrm{H}$ values by no more than $5 \%$. This means that the very high $\mathrm{H}$ values observed at high temperature are genuine and do not entail any elastic recovery effect.

Hence, in order to explain the unusual increase in the microhardness of gelatin films as a result of thermal treatment (Figure 1) one has to take into account the chemical peculiarities of this polymer. Being a polypeptide, in contrast to the chemically close to it polyamides, gelatin is characterized by the presence of a large amount of free (side-chain) carboxyl, 
hydroxyl and amino groups arising from the diamino-monocarboxylic and monoaminodicarboxylic acids.

It is well known that condensation polymers undergo additional condensation ${ }^{8,9}$ involving the end groups, when appropriate conditions are available (temperature, catalysts and vacuum are the main factors, accelerating the process) ${ }^{9}$. Similar interactions between reactive side chain groups can be expected in the case of proteins as previously reported ${ }^{10,11)}$. For instance, the insolubility of gelatin after sufficiently prolonged (several days) evacuation at temperatures between 65 and $105^{\circ} \mathrm{C}$ is explained by the formation of a three-dimensional network resulting from interchain cross-linking ${ }^{10)}$. This conclusion is supported by the fact that such an insolubility is not observed when chemically modified (by acetylation of the amino groups or by esterification of the carboxyl groups) gelatin is subjected to the same treatment $^{12 \text { ) }}$.

One can assume that as a result of formation of chemical links between chain segments, regardless of whether intra- or intermolecular, a denser chain packing will be achieved, which is comparable to that of chemically non-bounded chains or chain segments. Such a molecular densification may lead to increased microhardness as it is known that these two properties are very closely related ${ }^{25,6)}$.

In conclusion, one has to emphasize that thermally treated gelatin films exhibit surface microhardness values that are much larger than those of common synthetic polymers. This is most probably due to the occurrence of chemical cross-linking in gelatin as a result of thermal treatment. A more detailed study of these first observations as well as the elucidation of some potentials for their practical application are in progress. 


\section{Acknowledgments}

Grateful acknowledgment is due to DGICYT, Spain, for the support of this investigation (Grant PB94-0049). It is a pleasure to acknowledge the partial financial support provided by the National Science Foundation of U.S.A. through Grant INT-9514149 (Division of International Program). One of us (S.F.) is very pleased to acknowledge the tenure of a sabbatical grant from DGICYT, Madrid, Spain. 


\section{References:}

1) S. Fakirov, M.E. Cagiao, F.J. Baltá-Calleja, D. Sapundjieva, E. Vassileva, Colloid Polym. Sci. (submitted).

2) F.J. Baltá-Calleja, S. Fakirov, Trends Polym. Sci. 5, 246 (1997).

3) P.I. Rose, "Gelatin" in Encyclopedia of Polymer Science and Engineering, Eds. H.F. Mark, N.M. Bikales, C.G. Overberger, G. Menges, John Wiley \& Sons, New York, 2nd edition, 1987, vol.7, p. 488.

4) S. Fakirov, Z. Sarac, T. Anbar, B. Boz, I. Bahar, M. Evstatiev, A.A. Apostolov, J.E. Mark, A. Kloczkowski, Colloid. Polym. Sci. 275, 307 (1997).

5) F.J. Baltá-Calleja, Adv. Polym. Sci., 66, 117 (1985)

6) F.J. Baitá-Calleja, J. Martinez Salazar, D.R. Rueda in Encyclopedia of Polymer Science and Engineering, Eds. H.F. Mark, N.M. Bikales, C.G. Overberger, G. Menges, John Wiley \& Sons, New York, 2nd edition, 1987, p. 614.

7) W.P. Paplham, J.C. Seferis, F.J. Baltá Calleja, H.G. Zachmann, Polymer Composites, 16(5), 424 (1995).

8) P.J. Flory, "Principles of Polymer Chemistry", Cornell University Press, Ithaca, 1953.

9) S. Fakirov, "Solid state reactions in condensation polymers" in "Solid State Behavior of Linear Polyesters and Polyamides", Eds. J.M. Shultz, S. Fakirov, Prentice Hall, Englewood Cliffs, New Jersey, 1990.

10) I.V. Yannas, A.V. Tobolsky, Nature, 215, 509 (1967)

11) "The Science and Technology of Gelatin". Eds. A. Ward, A. Courts, Academic Press, London, New York, San Francisco, 1977.

12) J. Bello, H. Riese-Bello, Sci. Indust. Photograph., 29, 361 (1958). 


\section{Figure caption}

Figure 1. Temperature dependence of microhardness $\mathrm{H}$ on gelatin. The measurements were carried out on the same sample stored in a dessicator between the cycles. The open circle in Fig. 1a corresponds to the room conditioned (not-dried) gelatin film. 


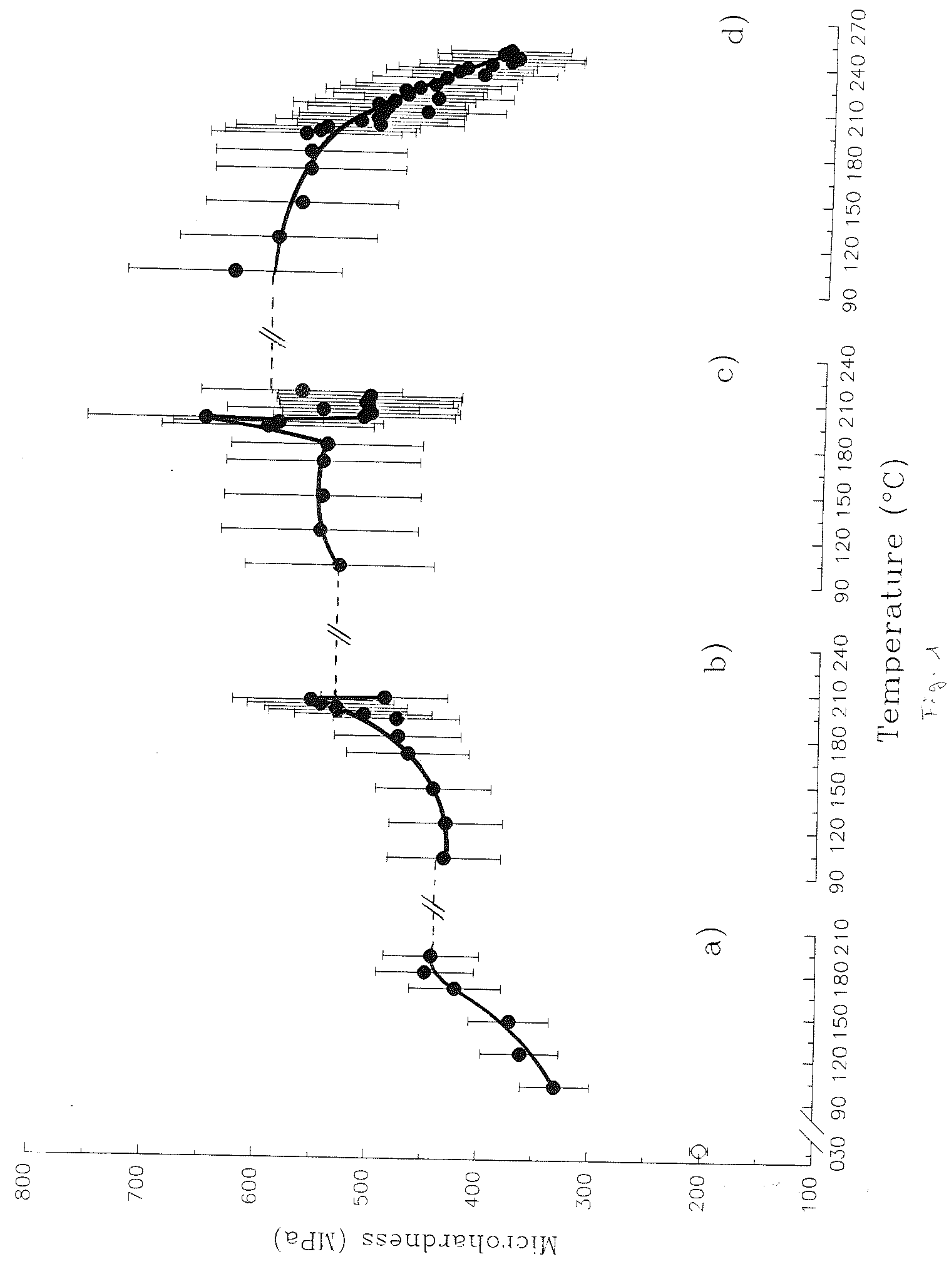

